\title{
AS FORMAS DE APRENDIZAGEM MAIS SIGNIFICATIVAS PARA OS ESTUDANTES DE ENFERMAGEM
}

\author{
THE MOST SIGNIFICANT LEARNING APPROACHES FOR NURSING STUDENTS
}

\author{
Lucimare Ferraz ${ }^{1}$ \\ Ivete Maroso Krauzer ${ }^{2}$ \\ Lurdes Chiossi da Silva ${ }^{3}$
}

Resumo Com o objetivo de conhecer as formas de aprendizagem mais significativas para os acadêmicos do curso de enfermagem de uma universidade situada na região Sul do Brasil, realizou-se uma pesquisa de natureza qualitativa com 37 acadêmicos no período de maio a junho de 2007. Os dados, inicialmente, foram coletados por um instrumento contendo apenas uma questão norteadora: “Qual é a forma que você melhor aprende o conteúdo?"; em seguida, reuniu-se um grupo focal com nove discentes, onde foi discutida e aprofundada a temática. Os resultados deste estudo apontam que esses acadêmicos de enfermagem aprendem melhor o conteúdo por meio de atividades teórico-práticas; onde podemos inferir que a aprendizagem se torna significativa para o estudante na medida em que ele visualiza a sua aplicabilidade no cotidiano das atividades executadas pela enfermagem.

Palavras-chave aprendizagem; discentes; enfermagem.
Abstract Seeking to get to know the most significant learning approaches for nursing students at a university located in Southern Brazil, a qualitative survey was carried out among 37 students from May to June 2007. Initially, the data were collected via an instrument containing a single guiding question: "How do you best learn content?". A group of nine students was then brought together and the theme explored in more detail. The results of this study indicate these nursing students learn content best via theoretical and practical activities. This allows us to infer that learning becomes more significant to students as they realize how such learning is applied in the daily activities nurses carry out.

Keywords learning, students; nursing. 


\section{Introdução}

A aprendizagem dos estudantes tem sido objeto de discussão no meio acadêmico, visto que a qualidade do ensino vem sendo questionada por educadores, comunidade e parceiros das atividades teórico-práticas. Tais discussões devem levar em consideração que a aprendizagem no processo de formação do profissional enfermeiro é um processo contínuo (Unochapecó, 1996).

Mortimer (2000) aponta que, apesar da grande variedade de diferentes abordagens e visões sobre aprendizagem, há pelo menos duas características principais que parecem ser compartilhadas: a aprendizagem se dá através do ativo envolvimento do aprendiz na construção do conhecimento; e as ideias prévias dos estudantes desempenham um papel importante no processo de aprendizagem.

Segundo Anastasiou e Alves (2005), as aprendizagens não se dão todas da mesma maneira, pois dependem do sujeito que aprende e do objeto a ser aprendido e o processo de apreensão pode se dar por imitação de um modelo, por repetição, por ensaio e erro ou descoberta.

Com relação à formação do profissional de enfermagem, Camacho e Santo (2001) destacam que o estudante aprende ao entrar em contato com as diversas faces do cuidar durante sua vida acadêmica, pois as ações que realiza, a identificação e as experiências durante sua graduação são diversificadas e dinâmicas, gerando momentos de interesse e participação.

Aprender na área da saúde é um fenômeno complexo, porque a formação desses profissionais necessita ir além da reprodução das técnicas e conhecimentos, já que, às vezes, tais conhecimentos são ineficazes em contextos cujas características são diferentes daqueles onde os conceitos foram produzidos (Stedile, Rech e Friendlander, 2003).

Neste processo de aprendizagem, o papel do docente na qualificação profissional do enfermeiro deve se constituir numa "formação que apresenta potencial para subsidiar ações de complexidade e imprevisibilidade, características do cotidiano de trabalho em saúde" (Silva e Sena, 2006, p. 118). Portanto, o profissional da área da saúde, além do conhecimento técnico, deve ter habilidades para aplicá-lo em diversas situações e realidades.

No intuito de contribuirmos efetivamente para a formação dos profissionais de enfermagem, com conhecimento técnico-científico para serem sujeitos críticos, reflexivos e resolutivos no desenvolvimento do seu trabalho, desenvolvemos este estudo com o objetivo de conhecer e compreender as formas de aprendizagem mais significativas para os acadêmicos do sétimo período do curso de enfermagem de uma universidade comunitária regional, localizada no sul do Brasil. 


\section{Metodologia}

Este trabalho é um estudo descritivo e de caráter qualitativo, que foi desenvolvido com acadêmicos do sétimo período do curso de enfermagem de uma universidade comunitária regional do oeste do estado de Santa Catarina. Os dados foram coletados nos meses de maio a junho de 2007. Trinta e sete acadêmicos matriculados na disciplina de Pesquisa em Enfermagem II participaram do estudo. Os dados, inicialmente, foram coletados por um instrumento contendo apenas uma questão norteadora: “Qual é a forma que você melhor aprende o conteúdo?"

Com base em tal informação, realizamos a análise dos relatos através da técnica de análise de conteúdo proposta por Bardin (2002), onde os depoimentos foram listados e as unidades de registros identificadas e categorizadas.

Posteriormente, buscando a compreensão das formas de aprendizado mais significativas apontadas pelo grande grupo, realizamos um grupo focal com nove discentes, de 21 a 33 anos de idade, que discutiram e aprofundaram a temática. A discussão no grupo focal é uma atividade evolutiva, porque na maioria das vezes surgem novas perguntas e questões relativas ao tema em estudo, tornando visível uma outra face da realidade (Krueger, 1989). Essa técnica possibilitou o aprofundamento de algumas questões pertinentes ao estudo, enriquecendo as informações previamente obtidas.

Os aspectos éticos desse estudo atenderam a resolução n. ${ }^{\circ}$ 10/196/96, capítulo VI, VI-5, do Conselho Nacional de Saúde, do Ministério da Saúde. Esta pesquisa teve seu projeto aprovado pelo Comitê de Ética em pesquisa da Unochapecó.

\section{Apresentação e discussão dos resultados}

Com o objetivo de desvendar as formas de aprendizagem mais significativas para os acadêmicos de enfermagem, desenvolvemos este estudo que 'apontou' três categorias que revelam como o acadêmico melhor aprende o conteúdo. Estas são: as atividades teórico-práticas, o professor e o método de estudo.

\section{Atividades teórico-práticas}

As atividades teórico-práticas no curso de enfermagem são desenvolvidas nos campos de assistência à saúde, como: hospitais, unidades de saúde, creches, asilos, policlínicas e outros. Nestes espaços, os acadêmicos 
atendem as pessoas, as famílias e as comunidades, sempre sob a supervisão de um professor.

Segundo os depoimentos dos acadêmicos participantes da pesquisa, eles aprendem melhor o conteúdo através das vivências nas atividades teórico-práticas. Os relatos a seguir evidenciam esta constatação:

Para mim, a melhor apreensão se deu e continua se formando através de aulas práticas e experiências do estágio (Acadêmico 1).

Aprendo mais praticando, o que pratico nunca, ou melhor, é difícil esquecer. O que mais me marcou mesmo foi o período de estágio, quando vamos, vemos e fazemos. (Acadêmico 2) .

A forma que mais aprendo os conteúdos é quando tenho que pôr em prática, na verdade é quando vejo e palpo, tem que ser mais concreto aos meus olhos (Acadêmico 3).

Tais depoimentos demonstraram a importância das atividades de ensino extra sala de aula, em que o acadêmico tem a oportunidade de relacionar e aplicar os conceitos teóricos na realidade apresentada. Segundo Feuerwerker e colaboradores (2005, p. 25), “a aprendizagem para ser significativa deve estar diretamente relacionada à experiência afetiva que o indivíduo vive".

Nesta perspectiva de ensino, Reibnitz e Prado ressaltam que:

Essa vivência da realidade precisa ser mediada por uma atitude investigativa e não por uma atitude passiva, contemplativa. Esse é o desafio do professor: fazer do espaço do mundo do trabalho, um espaço pedagógico de estímulo ao pensamento críticocriativo, utilizando a prática do julgamento para a análise e apreensão da realidade vivenciada, na perspectiva de intervir nesta realidade (Reibnitz e Prado, 2003, p. 29).

O processo de ensinar pode despertar, nos diferentes sujeitos envolvidos (professor e estudante), a necessidade de investigar e de desvelar a realidade, para que através de seu conhecimento, eles possam formular propostas adequadas de intervenção. Neste aspecto, o ato de ensinar e aprender necessita de uma mobilização constante de professores e estudantes na busca de alternativas que promovam o conhecimento.

Nesse pensar, Vasconcelos (1992, p. 30) diz que "a mobilização colocase como um momento especificamente pedagógico, em relação à teoria dialética do conhecimento, uma vez que esta supõe o interesse do sujeito em conhecer". Esta provocação para buscar o conhecimento torna efetiva a ação 
do sujeito (estudante), a qual desperta a curiosidade, fazendo com que o acadêmico aprenda com mais entusiasmo e que as experiências vividas nesse contexto sejam realmente significativas.

\section{O professor}

Quanto à participação do professor no processo de aprendizagem do acadêmico de enfermagem, constatamos que este desempenha um papel importante, porém, segundo os acadêmicos, há diferenças significativas entre os professores. Para eles, o professor desempenha um papel efetivo na aprendizagem quando demonstra 'domínio' do conteúdo da sua disciplina, quando relaciona a teoria com a prática e faz uso de uma didática atrativa e dinâmica. Neste caso, muitos alunos consideram "uma boa aula", didaticamente falando, quando o professor abre espaços para o diálogo, deixando também emergir questões da prática em saúde.

Os depoimentos a seguir ilustram as percepções dos acadêmicos de enfermagem sobre o papel do professor no processo de aprendizagem:

Quando o professor demonstra conhecimento sobre o assunto e segurança no que fala e ensina (Acadêmico 4).

Quando o professor consegue explicar o assunto sem precisar ficar lendo o conteúdo nos slides, uma aula expositiva com discussões, com exemplos práticos (Acadêmico 5).

O professor chegar em determinado paciente e falar seu problema, cuidados que poderíamos estar fazendo, trocando dúvidas, aluno versus professor, podendo colocar nossa opinião sem ter medo (Acadêmico 6).

Neste último depoimento, a variável 'medo' é mencionada. Segundo o discurso coletivo do grupo focal, o medo surge quando o professor tem uma postura de controlador, fiscalizador e avaliador. Os componentes do grupo explicaram que o medo, independente do professor, sempre está presente nas aulas práticas e afirmaram que este sentimento se dá pelo fato de que durante as aulas práticas vivenciam coisas novas, desconhecidas ou inesperadas.

Vale destacar que o cotidiano de enfermagem é diferente a cada dia, pois as situações, os procedimentos e os pacientes mudam constantemente, e a imprevisibilidade faz parte do universo de trabalho na área da saúde. Portanto, é compreensível que os acadêmicos se sintam inseguros nos espaços de prática, pois não sabem totalmente o que acontecerá durante estes 
momentos. Porém, os acadêmicos relataram que quando o professor é seguro, tranquilo, tem uma postura de facilitador e mostra compreensão em relação às limitações cognitivas e procedimentais do acadêmico, a insegurança relacionada à prática diminui significativamente.

Visando conhecer os adjetivos que constituem um bom professor, solicitamos que cada um dos acadêmicos participantes do grupo focal mencionasse uma qualidade e uma fragilidade que compõem o bom e o mau professor, conforme mostra o quadro abaixo.

Quadro 1

\begin{tabular}{cc}
\hline Os adjetivos do bom e do mau professor, segundo os acadêmicos de enfermagem, Chapecó, 2007 \\
\hline O bom professor é aquele que: & O mau professor é aquele que; \\
\hline tem compaixão & é autoritário \\
é humilde & é egoísta \\
é sincero & não tem humildade \\
tem sabedoria & é antipático \\
faz troca & é inseguro \\
é verdadeiro & é irritado \\
é facilitador & é torturador \\
é compreensivo & é estressado \\
é companheiro & é arrogante
\end{tabular}

Fonte: $\mathrm{o}$ autor

Percebe-se, por meio dessas opiniões, que as características de um bom ou mau professor não estão relacionadas com as habilidades técnicas da docência, mas sim com o comportamento do professor durante o processo de ensino ou perante a turma.

Em relação ao ensino na enfermagem, Prado, Reibnitz e Gelbcke (2006) apontam que o docente de enfermagem na sua prática pedagógica precisa cuidar do ser humano que está em formação, portanto é necessário o reconhecimento da sensibilidade como elemento plasmático na profissionalização do enfermeiro, sendo importante, neste caso, o uso da intuição, da emoção, da solidariedade e do bom senso.

Para Borsato, citado por Reibnitz, Horr e Souza (2000, p. 66), “o bom professor lidera e, de forma sutil, dirige democraticamente as atividades num respeito mútuo, conduzindo o processo pedagógico para o apreender". De fato, ensinar estudantes a aprender a aprender é um desafio para as escolas que pretendem formar indivíduos autônomos, capazes de tomar decisões (Stedile e Friendlander, 2003).

Sobre este aspecto, Pimenta e Anastasiou (2002) explicam que não há um modelo a ser seguido para a prática da docência, mas o professor deve ter habilidade para lidar com a imprevisibilidade, sendo flexível em relação 
a mudanças. Portanto, não existe uma única receita, o importante é que os professores conheçam todos os ingredientes que compõem o aprendizado e as suas formas de condensação, bem como o tempo de preparo para a finalização dos processos, que se diferenciam de acordo com o aprendiz e o espaço de apreensão.

Finalizando as questões referentes ao papel do professor, os acadêmicos do grupo focal destacaram a importância de ele ser 'justo' no momento da avaliação das vivências teórico-práticas, como podemos observar nos seguintes relatos:

Na hora da avaliação tem que ser justo. É aquela pessoa que tem bom senso (Acadêmico 7).

Às vezes, tu fazes e erras, e vais com uma nota mais baixa do que o colega que não fez, e portanto não errou (Acadêmico 8).

No caso da avaliação da prática em enfermagem, o professor, além de considerar os aspectos cognitivos e procedimentais, deve valorizar os aspectos de atitude, porém é imprescindível que os critérios de avaliação estejam claros e preestabelecidos entre o professor e o estudante. Igualmente, a nota deve ser apresentada sob os critérios nos quais ela foi construída, apontando assim as limitações e potencialidades do acadêmico naquele momento, já que acreditamos que o resultado de uma avaliação não deve ser o fim, mas parte do processo de aprendizagem.

Wachowicz e Romanowski (2002) propõem uma prática de avaliação formativa, que visa a ajustar os critérios da ação, onde os estudantes, junto com os professores, assumem o compromisso da conquista do conhecimento, no mais alto grau possível.

\section{Método de estudo}

No que diz respeito aos métodos de estudo dos acadêmicos, percebe-se que são desenvolvidos a partir de estudos individuais, coletivos e de pesquisas. Entre estes, a forma de aprendizagem apontada com maior ênfase foi o trabalho em grupo:

Nos reunimos em pequenos grupos para estudar, e justamente um ajuda o outro (Acadêmico 9).

Quando montamos grupos e o grupo todo participa, torna-se fácil aprender (Acadêmico 10). 
Achei mais facilidade em trabalhar em grupos com colegas. Ocorreu um caso que em quatro dias revi a matéria de um semestre todo e, com certeza, não esqueci mais (Acadêmico 11).

Os depoimentos acima mostram como os estudantes, mutuamente, incentivam uns aos outros para o aprendizado, pois, além do estímulo criado no estudo coletivo, os que têm um maior entendimento do conteúdo podem e devem sanar dúvidas que, muitas vezes, eles não têm a oportunidade de esclarecer com o professor. Dessa forma, o colega pode ser um tradutor ou um mediador da síntese de uma linguagem abstrata para o seu colega. Para Castanho, a prática de estudar em parceria é uma forma de cooperação intelectual (apud Reibnitz, Horr e Souza, 2000).

Entretanto, o trabalho em grupo exige habilidades de interação e respeito ao tempo de elaboração de cada indivíduo envolvido no processo coletivo de aprendizagem. Anastasiou e Alves corroboram com esse pensamento ao afirmarem que:

Trabalhar num grupo é diferente de fazer parte de um conjunto de pessoas, sendo fundamental a interação, o compartilhar, o respeito à singularidade, a habilidade de lidar com o outro em sua totalidade, incluindo suas emoções. Isso exige autonomia e maturidade, algo a ser construído paulatinamente com os alunos universitários (Anastasiou e Alves, 2005, p.76).

Para muitos acadêmicos de enfermagem, não há a disponibilidade de estudos em grupos na frequência que desejariam, pois trabalham e não dispõem de horário e tempo para tal atividade. Nesses casos, estudar sozinho passa a ser a alternativa mais apropriada. Entretanto, a prática do estudo individual exige esforço e persistência. Sendo assim, o professor pode desenvolver estratégias para despertar as potencialidades dos estudantes facilitando a apreensão do conhecimento, tornando-os aptos a gerir a sua formação/qualificação profissional.

\section{Considerações finais}

Ao findar o estudo, evidenciamos que a atividade teórico-prática foi considerada a forma mais significativa de aprendizado para os acadêmicos de enfermagem. Portanto, acreditamos ser imprescindível que esta prática formativa seja continuamente discutida e avaliada pelos acadêmicos, docentes, instituição de ensino e nos espaços onde se vivencia e se desenvolve o cuidado em saúde, para que estes momentos de aprendizagem possam contribuir efetivamente para o crescimento e desenvolvimento deste profissional. 
Assim, a formação em enfermagem deve ter em seus pressupostos uma prática educativa que contemple um processo interativo, vivenciado entre diversos sujeitos (professor, estudante, profissional de saúde, individuo e comunidade), implicando em corresponsabilidade e em participação de todos os envolvidos.

Levando-se em consideração que a enfermagem visa ao cuidado holístico que deve superar a fragmentação entre a biologia e o social, o curativo e o preventivo, o clínico e o epidemiológico, a subjetividade e a sociabilidade (Silva e Sena, 2006), a formação acadêmica deve primar por um espaço em que o futuro enfermeiro possa desenvolver as habilidades necessárias para um cuidado integral. Dessa forma, o professor constitui uma figura importante, podendo influenciar na postura e práxis do discente em formação.

Com relação ao papel do professor na formação do profissional enfermeiro, a citação a seguir representa as habilidades que um professor deve ter, apontadas pelos estudantes nesta pesquisa.

\footnotetext{
A aprendizagem, porém, não se baseia nas habilidades pedagógicas do professor, nem no conhecimento erudito que tem sobre o assunto, nem de seu planejamento curricular, nem na utilização que faz dos recursos audiovisuais, nem de suas predileções e exposições, nem de abundância de livros, embora em certas ocasiões cada um desses itens possa ser utilizado. Mas a aprendizagem se baseia na qualidade de atitudes que existem no relacionamento pessoal entre o professor (facilitador) e aquele que aprende (o aluno) (Clapis apud Zani, Nogueira, 2006, p. 99)
}

Quanto ao método de estudo em que os acadêmicos mais aprendem os conteúdos, destacam o trabalho em grupo, visto que, através da ajuda mútua e da socialização do conhecimento, o processo de aprendizagem é facilitado.

Por intermédio deste estudo, podemos inferir que a atividade teóricoprática desenvolvida ao longo do curso, tanto nos serviços de saúde como nas comunidades, é considerada a forma mais significativa de aprendizado para o estudante, já que ele visualiza a aplicabilidade da teoria no cotidiano do trabalho da enfermagem.

Finalizando, constatamos que os resultados deste estudo foram de suma importância para fornecer informações que subsidiarão as estratégias para o desenvolvimento de uma prática de aprendizagem baseada nas potencialidades do ensino. Outrossim, as informações nos proporcionaram referências para os próximos estudos de avaliação do processo de aprendizagem do projeto político-pedagógico do curso de enfermagem. 


\section{Notas}

1 Professora titular da Universidade Comunitária Regional de Chapecó (Unochapecó), Chapecó, Santa Catarina, Brasil. Mestre em Saúde Coletiva pela Universidade Luterana do Brasil (Ulbra). <lferraz@unochapeco.edu.br>

Endereço: Rua Minas Gerais, 19-E, apto. 802, Centro, Chapecó, Santa Catarina, Brasil. CEP 89801-015.

2 Professora titular da Universidade Comunitária Regional de Chapecó (Unochapecó), Chapecó, Santa Catarina, Brasil. Mestranda em Enfermagem do Programa de Mestrado Interinstitucional Universidade Federal de Santa Catarina/Unochapecó. <ivetek@unochapeco.edu.br>

3 Professora titular da Universidade Comunitária Regional de Chapecó (Unochapecó), Chapecó, Santa Catarina, Brasil. Mestre em Enfermagem pela Fundação Universidade Federal do Rio Grande (Furg). <lurdes@unochapeco.edu.br>

\section{Referências}

ANASTASIOU, Léa das G. Camargos; ALVES, Leonir P. (Orgs.) Processos de ensinagem na universidade: pressupostos para as estratégias de trabalho em aula. 5. ed. Joinville: Univille, 4.ed. Joinville: Univille, 2005. v. 1000. 145 p.

BARDIN, Laurence. El análisis de contenido. 3. ed. Madrid: Ahal, 2002.

CAMACHO, Alessandra C. L. Funchal; SANTO, Fátima H. do Espírito. Refletindo sobre o cuidar e ensinar na enfermagem. Revista Latino-Americana de Enfermagem, v. 9, n. 1, Ribeirão Preto, jan. 2001.

FEUERWERKER, Laura et al. Curso de formação de facilitadores de educação permanente. Unidade de aprendizagem práticas educativas no cotidiano do trabalho em saúde. Brasil. Ministério da Saúde, Fiocruz, 2005.

KRUEGER, Richard. A. Focus groups: a practical guide for applied research. Newbury Park, California: Sage, 1989.
MORTIMER, Eduardo F. Linguagem e formação de conceitos no ensino de ciências. Belo Horizonte: UFMG, 2000.

PIMENTA, Selma G.; ANASTASIOU, Léa das G. Camargos. Docência no ensino superior. São Paulo: Cortez, 2002.

PRADO, Marta L. do; REIBNITZ, Kenya S.; GELBCKE, Francine L. Aprendendo a cuidar: a sensibilidade como elemento plasmático para formação da profissional crítico-criativa em enfermagem. Texto \& Contexto Enfermagem, Florianópolis, v. 15, n. 2, p. 296-302, abr.-jun. 2006.

REIBNITZ, Kenya S.; HORR Lidvina; SOUZA, Maria de Lurdes (Orgs.). Aspectos operacionais do processo ensinar-aprender. Florianópolis: UFSC, NFR, SPB, 2000.

REIBNITZ, Kenya S.; PRADO, Marta L. do. Formação do profissional crítico-criativo: a investigação como atitude de (re)conhecimento do mundo. Texto \& Contexto Enfermagem. Florianópolis, v. 12, n. 1, p. 26-33, jan.-mar., 2003. 
SILVA, Kênia L.; SENA, Roseni R. de. A educação de enfermagem: buscando a formação crítico-reflexiva e as competências profissionais. Revista Latino-Americana de Enfermagem, v. 14, n.5, p.755-61, 2006.

STEDILE, Nilva; RECH, Lúcia; FRIENDLANDER, Maria R. Metacognição e Ensino de Enfermagem: Uma Combinação Possível?. Revista Latino-americana de Enfermagem, USP - São Paulo - SP, v. 11, n. 6, p. 792-799, 2003.

UNOCHAPECÓ. Projeto político pedagógico do curso de enfermagem. Unochapecó, 2006.

VASCONCELOS, Celso. Metodologia dialética em sala de aula. Revista $A E C$, v. 21, n. 83, p. 28-55. abr.-jun., 1992.
WACHOWICZ, Lilian Anna; ROMANOWSKI, Joana Paulin. Avaliação: que realidade é essa? Revista da Rede de Avaliação Institucional da Educação Superior, Campinas, v. 7, n. 2, p. 81-100, jun. 2002.

ZANI, Adriana V.; NOGUEIRA, Maria S. Incidentes críticos do processo ensinoaprendizagem do curso de graduação em enfermagem, segundo a percepção de alunos e docentes. Revista Latinoaericana de Enfermagem, v. 14, n. 5, p. 742-8, 2006.

Recebido em 17/03/2008

Aprovado em 05/02/2009 